Check for updates

Cite this: RSC Adv., 2019, 9, 31357

Received 18th August 2019

Accepted 18th September 2019

DOI: $10.1039 / c 9 r a 06462 a$

rsc.li/rsc-advances

\section{Novel waterborne polyurethanes containing long- chain alkanes: their synthesis and application to water repellency}

\begin{abstract}
Xiaoli Liu, (D) Xiaobin Zou, Zhen Ge, ${ }^{*}$ Wenguo Zhang and Yunjun Luo (DD *
In the fabric finishing field, the water repellents have received increasing interest in recent years and the development of a fluorine-free water repellent has become an attractive prospect. In this study, glyceryl monostearate-modified waterborne polyurethanes (GWPUs) with a branched structure act as water repellents, and were prepared from toluene diisocyanate, trimethylolpropane, hydroxypropyl polydimethylsiloxane, $\mathrm{N}$-methyldiethanolamine, and glyceryl monostearate (GMS). The water repellency and other properties of GWPUs with different GMS content, such as water resistance, hydrophobicity, and air permeability, were studied. The results show that the GMS content for optimum water repellency was 20 wt\%, which achieved the highest score (100 points) in a water repellency evaluation. As for the water repellent ability with a GMS content of $20 \mathrm{wt} \%$, the water absorption of a piece of film was reduced to $7.80 \%$, while the water contact angle of terylene coated by the water repellent rose to $148.0^{\circ}$.
\end{abstract}

\section{Introduction}

With the development of science and technology, the pursuit of fabric functionalization is increasing. ${ }^{1}$ There are numerous important emerging applications for functional fabrics, such as air filtration, and antibacterial and water repellency. ${ }^{2-4}$ Fabric functionalization is the finishing of the fabric's surface with an agent that possesses a unique structure, and can change the surface structure of the original fabric and offer a new function., ${ }^{5,6}$ Among them, water-repellent finishing is an important field. ${ }^{7-10}$ In recent years, waterborne polyurethanes have been widely applied to textiles, leather, paper, and used in other fields as a result of their benefits from excellent environmental friendliness, security, and energy-saving properties. The water repellency of fabric can be increased by using waterborne polyurethane. ${ }^{11}$ Nevertheless, some drawbacks exist, such as poor water resistance and limited weather resistance, and restricted extensive practical applications of waterborne polyurethanes as water repellents. Generally, some lowsurface-energy compounds such as fluorochemicals, organosilicon complexes, and long-chain alkane substances can be introduced to add enhancements such as self-cleaning and antifouling properties, and increase the water repellency of waterborne polyurethane. ${ }^{12-17}$

Fluorochemicals have a wide application and play an indispensable role as water repellents because the fabrics coated with them exhibit water-repellency and self-cleaning performance, as well as breathability. ${ }^{18-21}$ However, most of them release biologically toxic substances, resulting in such serious damage to ecosystems

School of Materials Science and Engineering, Beijing Institute of Technology, Beijing, 100081, China. E-mail: gzandlsy@bit.edu.cn; yjluo@bit.edu.cn; Fax: +86-01068911608; Tel: +86-010-68911608 that many countries and organizations have limited their applications by issuing relevant laws and regulations. ${ }^{22,23}$ Therefore, the development of fluorine-free water repellents has become a significant trend.

One valid approach is introducing organic silicone into the water repellent because silicone exhibits hydrophobic properties, except when it is added to a fluorine-containing compound. ${ }^{24-26}$ Polydimethylsiloxane, which has high silicon-oxygen bond energy, low surface energy, and molecular chain flexibility, can provide good heat resistance, weather resistance, and water repellency to coatings. ${ }^{27}$ Long-chain alkane substances have also been applied to avoid the use of fluorinated compounds. Glyceryl monostearate, which contains a long-chain hydrophobic alkane group, can increase the content of long-chain alkane in the molecule and hydrophobicity of the fabrics if introduced into the water repellent. ${ }^{28}$ In addition, trimethylolpropane is a trihydric alcohol that is incorporated into waterborne polyurethane to provide a branched structure. $^{29}$ The introduction of these materials into waterborne polyurethane could effectively reduce its surface energy and enhance its water repellency so that the material could be manufactured into rain coats, medical bandages, tents, and other items..$^{30,31}$

In this study, glyceryl monostearate-modified waterborne polyurethanes (GWPUs), as water repellents with a branched structure, were prepared by combining polydimethylsiloxane and glyceryl monostearate. Fourier transform infrared (FTIR) spectroscopy, particle size distribution analysis, zeta potential analysis, water resistance analysis, static contact angle, surface energy analysis, spray analysis, and X-ray photoelectron spectroscopy were used to investigate the structure and properties of the prepared water repellents. 


\section{Experimental}

\subsection{Materials}

Glyceryl monostearate (GMS, AR, $99.5 \mathrm{wt} \%$ purity) was purchased from Guangzhou Jiadele Biochemical Technology Co., Ltd. Toluene diisocyanate (TDI, industrial grade, 98 wt\% purity) was supplied by Bayer Corp. Hydroxypropyl polydimethylsiloxane (PDMS, $\mathrm{Mn}=2000 \mathrm{~g} \mathrm{~mol}^{-1}$, industrial grade, 98 wt\% purity) was available from Shanghai Sili Industry \& Trade Co., Ltd. Trimethylolpropane (TMP, AR, 99 wt\% purity) and $N$-methyldiethanolamine ( $N$-MDEA, AR, $99 \mathrm{wt} \%$ purity) were purchased from Tianjin Guangfu Fine Chemical Research Co. Ltd. Acetic acid (HAc, AR, 99.5 wt\% purity) and acetone (AC, AR, 99.5 wt\% purity) were supplied by Beijing Tongguang Chemical Co. Ltd. Dibutyltin dilaurate (DBTDL, AR, 99.5 wt\% purity) was available from Tianjin Damao Chemical Reagent Co. Ltd. Butanone oxime (AR, $99.5 \mathrm{wt} \%$ purity) was supplied by Sinopharm Chemical Reagent Co., Ltd.

\subsection{Preparation of GWPU}

2.2.1 Preparation of the emulsions. Glyceryl monostearatemodified waterborne polyurethane (GWPU) has a branched structure and can act as a water repellent (Fig. 1). To obtain it, first, quantitative TDI, PDMS, and TMP were added to a threenecked, round-bottomed flask equipped with a mechanical stirrer, thermometer, and reflux condenser with drying tube, and were dried under vacuum at $110{ }^{\circ} \mathrm{C}$ for $40 \mathrm{~min}$. Then, the mixture was stirred at $90{ }^{\circ} \mathrm{C}$ under a water-free environment for $3 \mathrm{~h}$, yielding NCO-terminated prepolymer 1 . Second, quantitative dry glyceryl monostearate (GMS) and a few drops of catalyst DBTDL were added, diluted with a small amount of acetone, and then reacted at $90{ }^{\circ} \mathrm{C}$ for another $3 \mathrm{~h}$, yielding prepolymer 2 . The system temperature was cooled to below $40{ }^{\circ} \mathrm{C}$. An acetone solution of $\mathrm{N}$-MDEA ( $6 \mathrm{wt} \% \mathrm{GWPU}$ ) as a cationic chain extender was slowly added into the flask over a $0.5 \mathrm{~h}$ period, and some acetone was also added to the system to adjust the viscosity of the mixture during the progress of the reaction. Then, the reaction proceeded at $40{ }^{\circ} \mathrm{C}$ for $1 \mathrm{~h}$. After that, quantitative butanone oxime was added, and the reaction continued for $0.5 \mathrm{~h}$. Third, after addition of HAc, the reaction was carried out at room temperature for $20 \mathrm{~min}$. After neutralization, the prepolymer was poured into some distilled water and dispersed by stirring at $2500 \mathrm{rpm}$ for $10 \mathrm{~min}$, finally yielding a GWPU emulsion. The solid content of the GWPU emulsion was $30 \mathrm{wt} \%$, and the molar ratio of $-\mathrm{NCO} /-\mathrm{OH}$ of the reactants was 1.4.

The prepared GWPU samples are listed in Table 1 . The numbers in the sample designation represent the content (wt\%) of GMS in the total reaction materials.

2.2.2 Preparation of the films. At room temperature, films were obtained by pouring a certain quantity of emulsions into PTFE moulds and then drying at room temperature for more than 7 days. Subsequently, the prepared polyurethane films were dried under vacuum at $70{ }^{\circ} \mathrm{C}$ for $12 \mathrm{~h}$ to remove the residual solvent.

2.2.3 Preparation of the fabric samples. GWPU emulsions were initially diluted to $100 \mathrm{~g} \mathrm{~L}^{-1}$. Then, fabric samples were immersed in the emulsions for approximately $1 \mathrm{~min}$. The coated fabric samples were dried under vacuum at $170{ }^{\circ} \mathrm{C}$ for 2 min. Two spinning cloth samples, terylene and pongee, were utilized for testing in this study.

\subsection{Characterization and testing}

\subsubsection{Characterization of GWPU}

(1) FTIR spectroscopy. FTIR spectra of the prepared films were tested using a Nicolet 8700 Fourier transform infrared spectrometer. The spectra were collected between $4000 \mathrm{~cm}^{-1}$ and $500 \mathrm{~cm}^{-1}$ with a resolution of $4 \mathrm{~cm}^{-1}$. Each sample was scanned 32 times, and the air was taken as a background peak.

(2) Particle size and zeta potential test. One or two drops of emulsion were added to distilled water and diluted to onethousandth mass fraction. The particle size and zeta potential of GWPU were determined at $25^{\circ} \mathrm{C}$ in $120 \mathrm{~s}$ using a Zetasizer Nano ZS90 laser particle sizer (Malvern Company).

(3) Viscosity test. The polyurethane emulsions were subjected to a shear viscosity test using a Brookfield programmable DV-II+ rotational viscometer with a No. 0 rotor at $25{ }^{\circ} \mathrm{C}$.

(4) Stability test. Stability tests of the samples were carried out using a HC-3018 high speed centrifuge (ZONKIA, China) at a speed of $3000 \mathrm{rpm}$ for $15 \mathrm{~min}$. If there was no sediment after centrifugation, the sample was considered stable for 6 months.

(5) DSC test. Differential scanning calorimetry (DSC) of the GWPU films was performed with a METTLER TGA/DSC1 thermogravimetric analyzer at a scanning rate of $10{ }^{\circ} \mathrm{C} \mathrm{min}{ }^{-1}$ from -150 to $150{ }^{\circ} \mathrm{C}$ under a $\mathrm{N}_{2}$ atmosphere.

(6) Water resistance test. The water absorption of the films was analyzed by immersing a known weight $\left(m_{0}\right)$ of the dried sample $(20 \mathrm{~mm} \times 20 \mathrm{~mm})$ into a beaker containing distilled water for $24 \mathrm{~h}$ at $25{ }^{\circ} \mathrm{C}$. After absorption, the wet sample was removed, the surface water was removed with a filter paper, and then, the sample was reweighed $(m)$. The water absorption $(W)$ was then calculated as:

$$
W=\left(m-m_{0}\right) / m_{0} \times 100
$$

(7) Static contact angle test. The static contact angle of the films was tested using an OCA20 contact angle goniometer (Germany) by the sessile drop method. Double-distilled water was applied as a probe liquid, and the droplet volume was $2 \mu \mathrm{L}$. All measurements are represented by the mean values of five runs.

(8) Surface free energy. The contact angle values of three types of pure liquid (water, diiodomethane, and formamide) on the surface of GWPU films were entered into the surface energy calculation software of the Dataphysics DACT21 surface energy tension goniometer. Then, the surface energy of the solid film $\gamma_{\mathrm{sv}}$, the dispersion force $\gamma_{\mathrm{sv}}{ }^{\mathrm{d}}$, and the polarity force $\gamma_{\mathrm{sv}}{ }^{\mathrm{p}}$ were calculated by the software according to the equation:

$$
\begin{gathered}
\gamma_{\mathrm{SV}}=\gamma_{\mathrm{SV}}^{\mathrm{p}}+\gamma_{\mathrm{SV}}^{\mathrm{d}} \\
r_{\mathrm{LV}}(1+\cos \theta)=\sqrt[2]{r_{\mathrm{SV}}^{\mathrm{d}} r_{\mathrm{LV}}^{\mathrm{d}}}+\sqrt[2]{r_{\mathrm{SV}}^{\mathrm{p}} r_{\mathrm{LV}}^{\mathrm{p}}}
\end{gathered}
$$




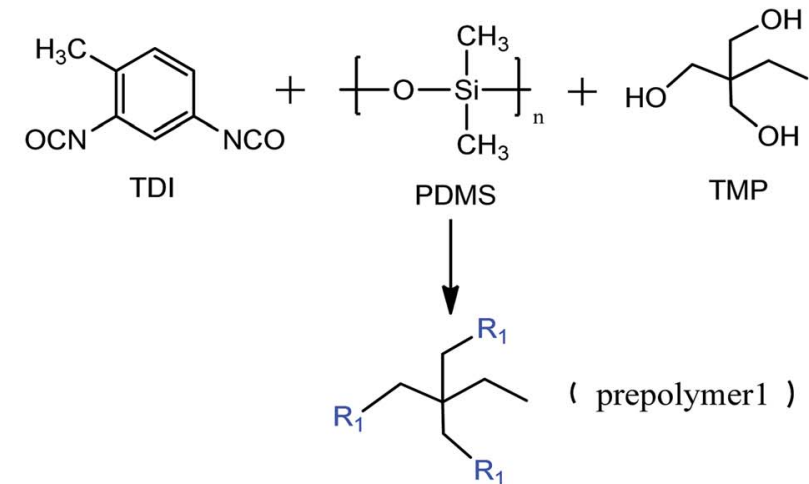

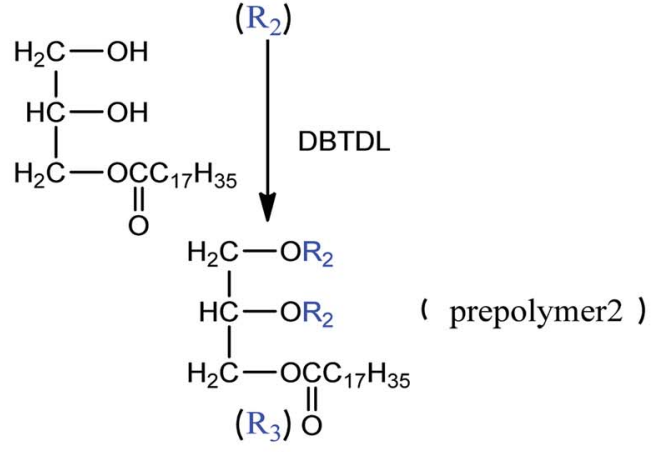<smiles>CN(O)C(O)N(C)C(O)O</smiles><smiles>[R9]CN(C)CO[R9]</smiles><smiles>CCC(C)=NO</smiles><smiles></smiles>

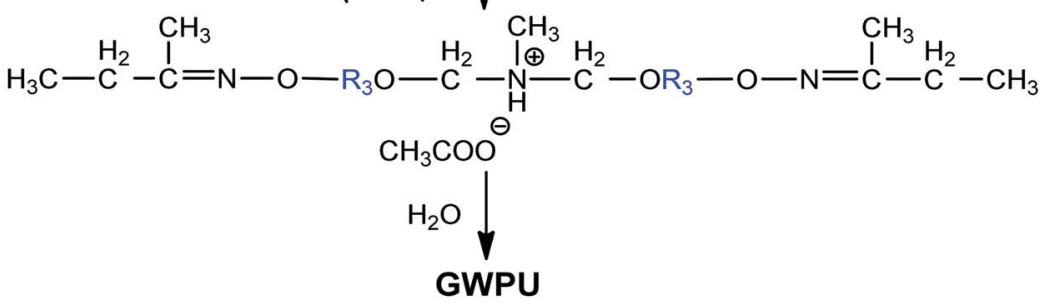<smiles>[R17]=[W]=O</smiles>

Fig. 1 Preparation of GWPU.

where $\gamma_{\mathrm{LV}}$ is the surface tension of the wetting liquid, and $\gamma_{\mathrm{LV}}{ }^{\mathrm{d}}$ and $\gamma_{\mathrm{LV}}{ }^{\mathrm{p}}$ are the dispersive and polar components, respectively. The known surface energy parameters of water, formamide, and diiodomethane in the software are listed in Table 2.
(9) Scanning electron microscopy (SEM). The morphology of the GWPU films was examined using a S-4800 scanning electron microscope. Micrographs were taken at $10000 \times$ magnification 
Table 1 GWPU samples with different GMS content

\begin{tabular}{llllllll}
\hline GMS (wt $\%)$ & 0 & 5 & 10 & 15 & 20 & 25 & 30 \\
\hline Sample designation & GWPU-0 & GWPU-5 & GWPU-10 & GWPU-15 & GWPU-20 & GWPU-25
\end{tabular}

Table 2 Surface energy parameters of three types of liquid

\begin{tabular}{llcl}
\hline Liquid sample & $\gamma_{\mathrm{LV}}\left(\mathrm{mN} \mathrm{m}^{-1}\right)$ & $\gamma_{\mathrm{LV}}{ }^{\mathrm{P}}\left(\mathrm{mN} \mathrm{m}^{-1}\right)$ & $\gamma_{\mathrm{LV}}{ }^{\mathrm{d}}\left(\mathrm{mN} \mathrm{m}^{-1}\right)$ \\
\hline Water & 72.8 & 51.0 & 21.8 \\
Formamide & 58.0 & 19.0 & 39.0 \\
Diiodomethane & 50.8 & 0.0 & 50.8
\end{tabular}

with a resolution of $2 \mu \mathrm{m}$, while the cross-sectional micrographs were taken with a resolution of $5 \mu \mathrm{m}$.

\subsubsection{Characterization of the fabrics treated with GWPU}

(1) Spray test. The spray method is a primary technique for evaluation of water repellency of fabric in the industry as per AATCC $22-2014 .^{32}$ A spray test of fabric samples subjected to waterproofing treatment was evaluated using a spray-type water repellency tester. Each test specimen was conditioned at $21 \pm$ $1{ }^{\circ} \mathrm{C}$ and $65 \pm 2 \%$ relative humidity for a minimum of $4 \mathrm{~h}$ before testing. Each specimen was assigned a rating corresponding to the nearest level on the rating chart (Fig. 2).

(2) Air permeability. The fabric samples after the padding treatment were placed in the standard atmosphere, which was $21 \pm 1{ }^{\circ} \mathrm{C}$ and $65 \pm 2 \%$ relative humidity, for $24 \mathrm{~h}$. Then, the air permeability of the specimen was tested with an AATCC windproof and permeability tester as per ASTM D-737.

(3) XPS test. The types and content of surface elements of GWPU films and fabrics were tested by a PHI Quantera II scanning microstrip X-ray photoelectron spectroscope (UlvacPHI). The X-ray photoelectron spectroscopy test depth followed the formula: $d=d_{\max } \sin \theta$, where $\theta$ is the take-off angle, and $d_{\max }$ is the maximum test depth of the $\mathrm{X}$-ray photoelectron, which is generally approximately $10 \mathrm{~nm}$ for polyurethane material. ${ }^{33} \mathrm{X}$-rays were radiated by a monochromatic $\mathrm{Al} \mathrm{K} \alpha \mathrm{X}$-ray source $(1486.6 \mathrm{eV})$ at $25 \mathrm{~W}$ and $15 \mathrm{kV}$. Take-off angles were selected as $20^{\circ}, 40^{\circ}$, and $90^{\circ}$ and corresponded to the coating

\section{STFNDARD SPRAY TEST RATINGS}
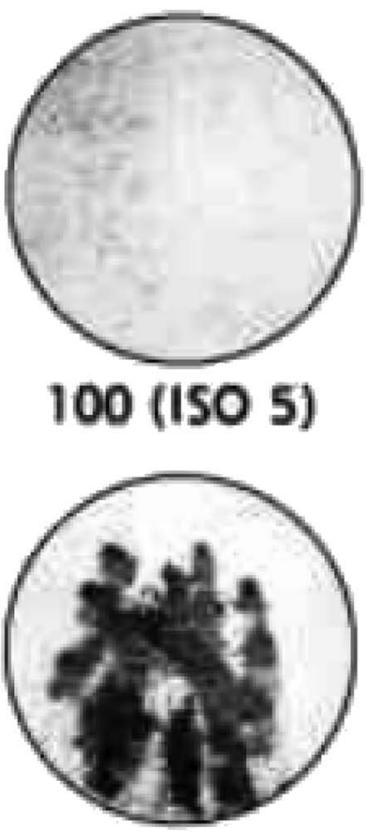

70 (ISO 2)
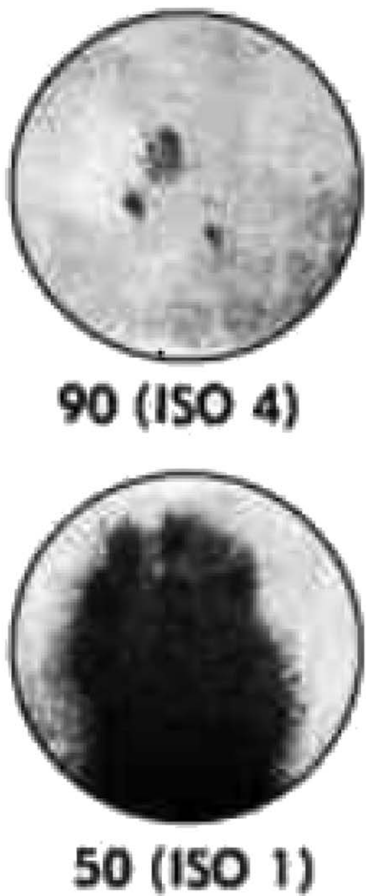
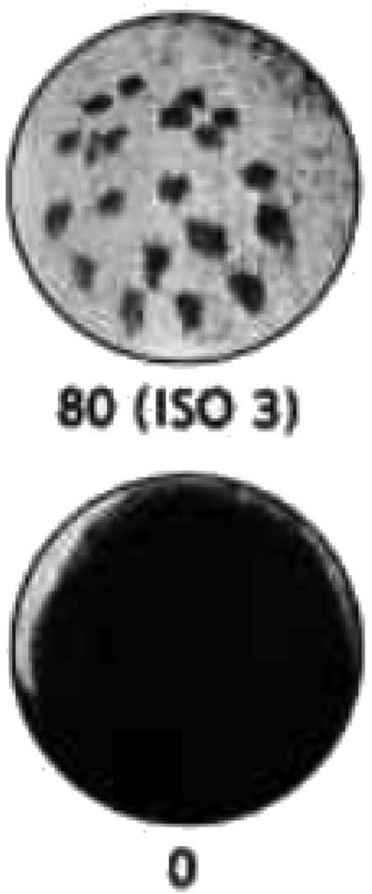

Fig. 2 Standard spray test ratings: 100 points - no sticking or wetting of the specimen face; 90 points - slight sticking or wetting of the specimen face; 80 points - wetting of the specimen face at the spray points; 70 points - partial wetting of the specimen face beyond the spray point; 50 points - complete wetting of the entire specimen face beyond the spray points; 0 points - complete wetting of the entire face of the specimen. 


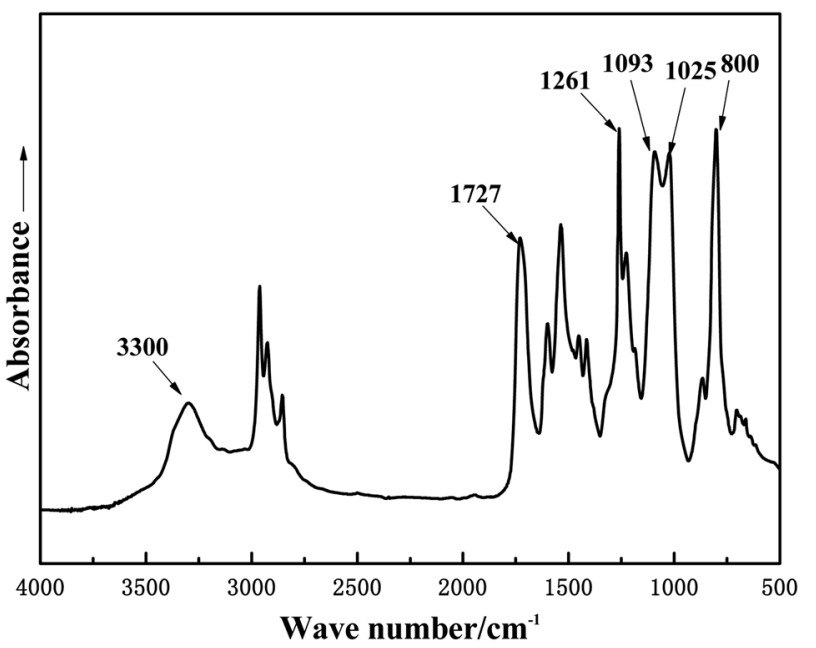

Fig. 3 FTIR spectrum of GWPU-20.

depths of $3.4 \mathrm{~nm}, 6.4 \mathrm{~nm}$, and $10 \mathrm{~nm}$, respectively. The full scan pass energy was $280.00 \mathrm{eV}$, and the step length was $1.00 \mathrm{eV}$. The test was calibrated at $284.8 \mathrm{eV}$, which was the peak position of $\mathrm{C}$ 1s. Narrow scan spectra of $\mathrm{C} 1 \mathrm{~s}, \mathrm{O} 1 \mathrm{~s}, \mathrm{~N} 1 \mathrm{~s}$, and Si 2p were collected, and peak analysis was carried out using PHI-MATLAB software.

\section{Results and discussion}

\subsection{FTIR characterization of GWPU}

The FTIR spectra of GWPU films were roughly similar, and one of them (GWPU-20) is presented in Fig. 3. It can be seen that the absorption peaks at $3300 \mathrm{~cm}^{-1}(\mathrm{~N}-\mathrm{H}$ stretching vibration), $1727 \mathrm{~cm}^{-1}\left(\mathrm{C}=\mathrm{O}\right.$ stretching vibration), and $1530 \mathrm{~cm}^{-1}(\mathrm{~N}-\mathrm{H}$ out-of-plane bending) corresponded to the formation of urethane ( $\mathrm{NH}-\mathrm{COO}-$ ) by reaction of the $-\mathrm{NCO}$ group and $-\mathrm{OH}$ group. The disappearance of the absorption peak at $2225 \mathrm{~cm}^{-1}$ (NCO group stretching vibration) demonstrated that raw materials had completely reacted and formed a polyurethane structure. The absorption peaks at $1261 \mathrm{~cm}^{-1}\left(-\mathrm{CH}_{3}\right.$ bending vibration of $\left.\mathrm{Si}-\mathrm{CH}_{3}\right), 1025-1093 \mathrm{~cm}^{-1}$ (C-O-C and $\mathrm{Si}-\mathrm{O}-\mathrm{Si}$ stretching vibration), and $800 \mathrm{~cm}^{-1}\left(-\mathrm{CH}_{3}\right.$ rocking vibration of $\left.\mathrm{Si}-\mathrm{CH}_{3}\right)$ in the FTIR spectrum were assigned to polydimethylsiloxane chain segments. In summary, these results

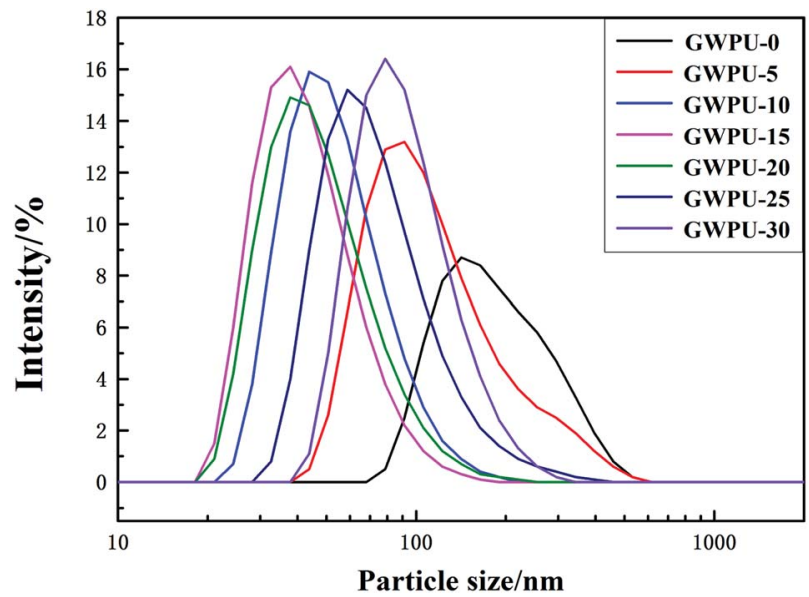

Fig. 4 Particle size distribution of GWPU

indicated that waterborne polyurethane modified by GMS had been successfully prepared.

\subsection{Appearance and stability of GWPU}

The stability of GWPU, including the latex emulsion appearance, storage stability, and zeta potential before and after modification are shown in Table 3. With the increase in the GMS content, the appearance of the GWPU emulsion gradually changed from milky white to a translucent emulsion with a generic blue color. When the GMS content was greater than $5 \mathrm{wt} \%$, all of the emulsions were stable without sediment, which was consistent with the results of zeta potential tests. When the zeta potential value was larger than $50 \mathrm{mV}$, the emulsion was more stable. The storage stability test period of these emulsions was 6 months. However, when the GMS content was less than $5 \mathrm{wt} \%$, there was a small amount of sediment in the emulsion. This was mainly due to the fact that a decrease in the GMS content led to a relative increase in the content of PDMS, which implied that there was an increase in the hydrophobic segment, which would deteriorate the stability of the emulsion.

\subsection{Particle size and viscosity of GWPU}

The particle size distribution of GWPU is shown in Fig. 4, and the particle size and viscosity of GWPU are shown in Fig. 5. The particle size of the emulsions tended to initially decrease and

Table 3 Appearance and stability of GWPU

\begin{tabular}{|c|c|c|c|}
\hline Sample & $\begin{array}{l}\text { Appearance of the } \\
\text { emulsion }\end{array}$ & Storage stability & $\begin{array}{l}\text { Zeta potential } \\
(\mathrm{mV})\end{array}$ \\
\hline GWPU-0 & Milky white & Little sediment & 45 \\
\hline GWPU-5 & Milky white, uniform & No sediment & 51 \\
\hline GWPU-10 & Translucent, blue & No sediment & 54 \\
\hline GWPU-15 & Translucent, blue & No sediment & 53 \\
\hline GWPU-20 & Translucent, blue & No sediment & 56 \\
\hline GWPU-25 & Translucent, blue & No sediment & 62 \\
\hline GWPU-30 & Translucent, blue & No sediment & 63 \\
\hline
\end{tabular}




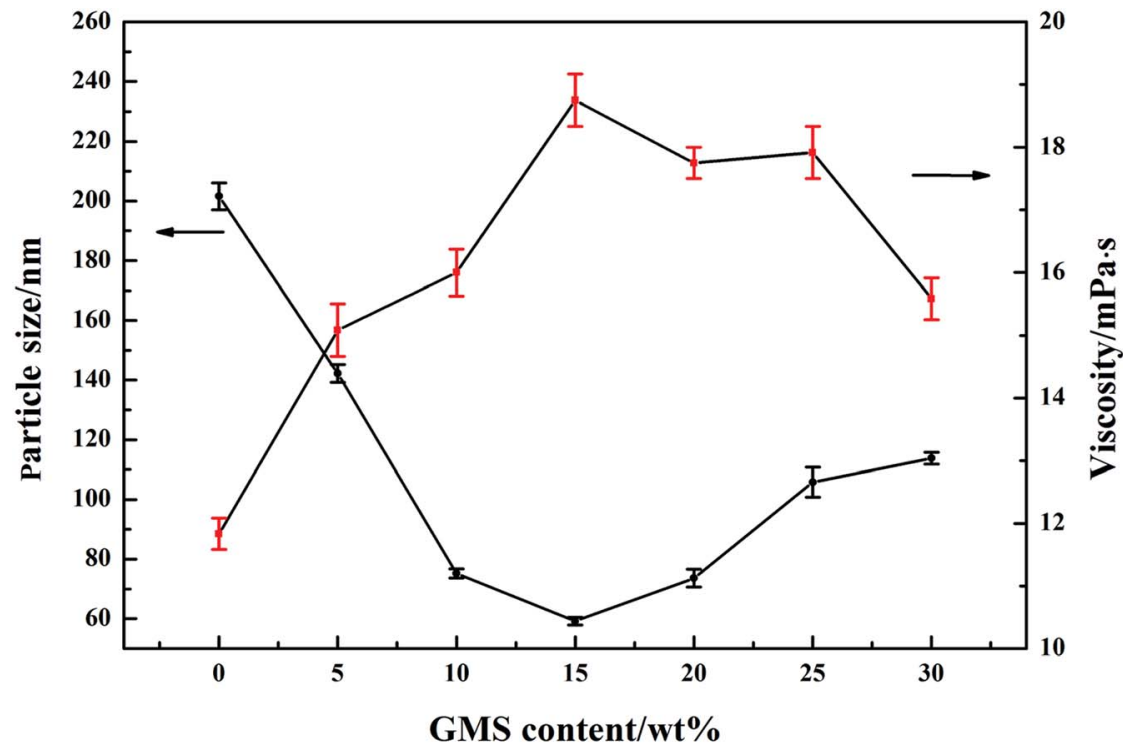

Fig. 5 Particle size and viscosity of GWPU.

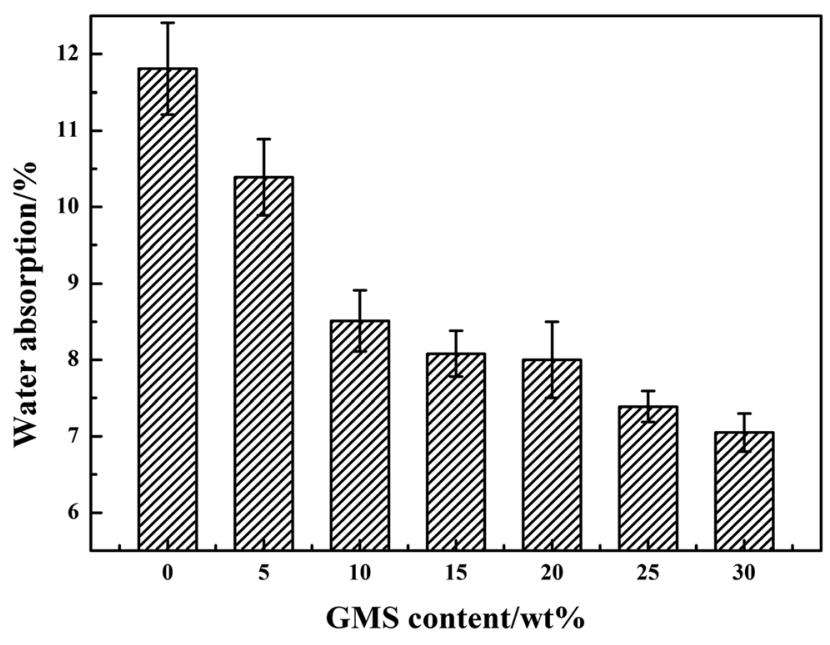

Fig. 6 Water absorption of GWPU films.

then increase with the increase in the GMS content. When the GMS content was less than $15 \mathrm{wt} \%$, upon increase, the hydrophobicity of the molecular chain increased, and the interentanglement between the molecular chains decreased, which increased the number of latex particles and reduced the particle size. When the GMS content was $15 \mathrm{wt} \%$, the size of particles was minimized. If the particle size was smaller, the GWPU molecular chain exhibited a stretched state, which resulted in a larger fluid volume and specific surface area of latex particles. Therefore, the viscosity of GWPU increased, while the particle size deceased with increasing GMS content. However, when the GMS content was greater than $15 \mathrm{wt} \%$, the fraction of the hard segment increased, which was harmful to a reverse process of the phase during emulsification, and therefore, the particle size increased, while the viscosity of the emulsion decreased.

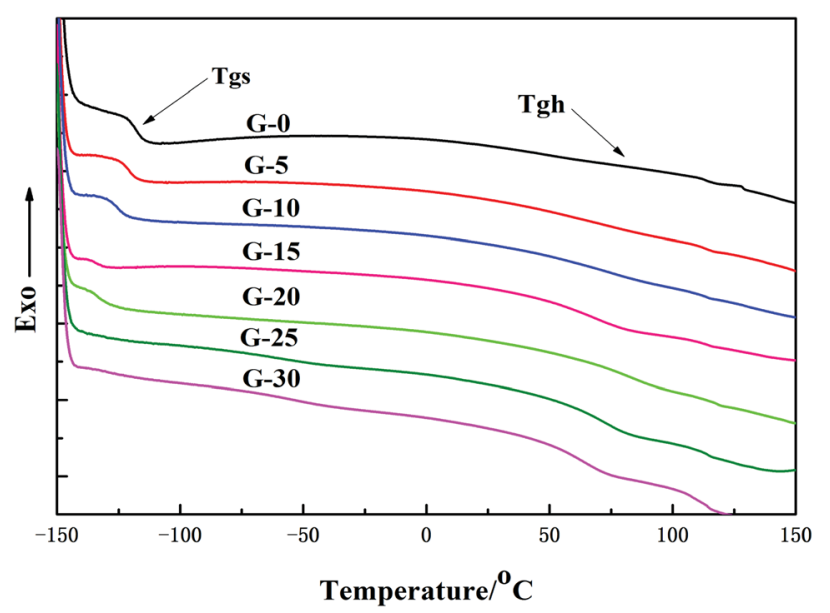

Fig. 7 DSC curves of GWPU films with different GMS content.

Table $4 T_{\mathrm{g}}$ values of GWPU films with different GMS content

\begin{tabular}{llll}
\hline Sample & $T_{\mathrm{gs}}{ }^{\circ} \mathrm{C}$ & $T_{\mathrm{gh}} /{ }^{\circ} \mathrm{C}$ & $\Delta T_{\mathrm{g}} /{ }^{\circ} \mathrm{C}$ \\
\hline GWPU-0 & -120.13 & 67.53 & 187.66 \\
GWPU-5 & -121.32 & 68.25 & 189.57 \\
GWPU-10 & -125.07 & 69.33 & 194.40 \\
GWPU-15 & -128.83 & 70.57 & 199.40 \\
GWPU-20 & -130.14 & 70.81 & 200.95 \\
GWPU-25 & -130.09 & 71.02 & 201.11 \\
GWPU-30 & -131.26 & 71.44 & 202.70
\end{tabular}

\subsection{Water absorption of GWPU}

As presented in Fig. 6, it is apparent that with the increase in the GMS content, the water absorption of the GWPU films slightly decreased. This can be explained as follows: when the GMS 


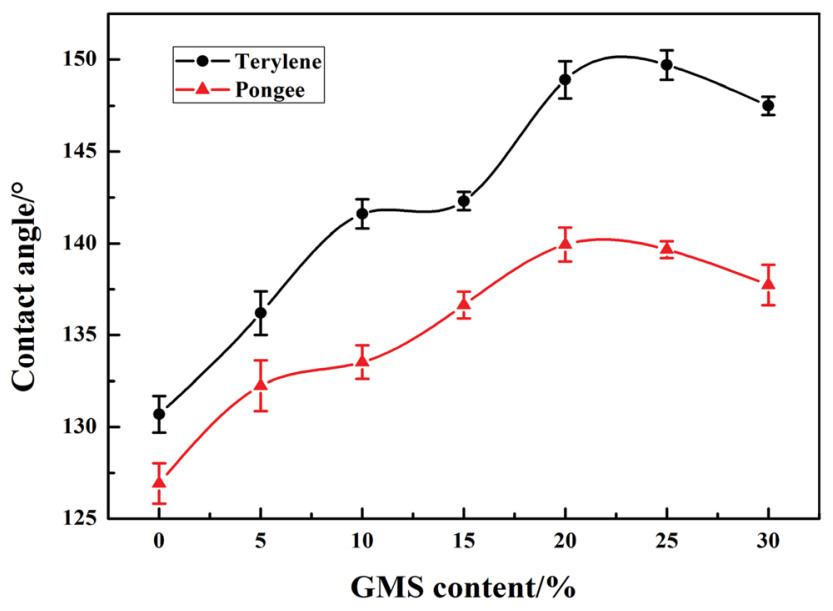

Fig. 8 Water contact angles of fabrics treated with GWPU possessing different GMS content.

content was lower, the siloxane content in the system was relatively greater, which resulted in the separation of the films and the clutter of molecular chain segments. The soft segment formed an amorphous region because of the thermal movement of the molecular chain, and thus, a gap was created. Subsequently, the water molecules were more likely to enter the interior of the films, resulting in a higher water absorption rate. When the GMS content rose, the siloxane content in the system fell while the polar urethane (NH-COO-) in the molecular chain rose, and the interaction between molecular chains also increased; consequently, the water resistance of the films increased.

\subsection{DSC analysis}

The DSC thermographs corresponding to the GWPU films are shown in Fig. 7, and the values of the glass transition of the soft segments and hard segments are summarized in Table 4 . It can be seen that with the increase in the GMS content, the glass transition temperature of the soft segments $\left(T_{\mathrm{gs}}\right)$ shifted to a lower temperature, while the glass transition temperature of the hard segments $\left(T_{\mathrm{gh}}\right)$ shifted to a higher temperature, and thus, the values of $\Delta T_{\mathrm{g}}\left(T_{\mathrm{gh}}-T_{\mathrm{gs}}\right)$ increased. This can be explained as follows: the increase in the GMS content led to an increase in the hard segments and an increase in the interaction between the hard segments. Therefore, the $T_{\text {gh }}$ moved toward a higher temperature due to the phase separation. Also, the movement of the soft segments was freer, and $T_{\mathrm{gs}}$ gradually moved toward a lower temperature; as a result, the $\Delta T_{\mathrm{g}}$ increased.

\subsection{Static contact angle of fabrics}

Fig. 8 illustrates the water contact angle of the fabrics coated with GWPU. As the GMS content of GWPU increased, the water contact angle slightly decreased. This occurred because with an increase in the GMS content, the long-chain alkane content in the water-repellent molecules also increased, which indicated that more $-\mathrm{CH}_{2} \mathrm{CH}_{3}$ was able to neatly arrange on the fabric surface, effectively forming a water-repellent layer. ${ }^{34}$ Nevertheless, when the GMS content exceeded $20 \mathrm{wt} \%,-\mathrm{CH}_{2} \mathrm{CH}_{3}$ would enrich on the surface and tend to saturate. Additionally, the adhesion of the particles to the fabric surface decreased due to the increased particle size of the emulsion, and thus, the water contact angle of the fabrics showed a decreasing trend. These results indicated that there was an optimum GMS content to achieve the most optimal water contact angle for fabrics coated with GWPU.

\subsection{Surface energy of GWPU}

With regard to surface energy (Table 5), the GWPU films with different GMS content demonstrated different results. When the GMS content increased from $0 \%$ to $20 \mathrm{wt} \%$, the surface energy of the GWPU films showed a slightly decreasing trend, while the contact angle increased. This was mainly due to the fact that many $-\mathrm{CH}_{2} \mathrm{CH}_{3}$ molecules were neatly arranged on the surface, which effectively reduced the surface energy of the films. When the content of GMS was further increased, the amount of $-\mathrm{CH}_{2} \mathrm{CH}_{3}$ tended to be saturated, resulting in the excessive $-\mathrm{CH}_{2} \mathrm{CH}_{3}$ being deposited on the surface of the film, with a deterioration of the regularity. Therefore, the surface energy increased, while the contact angle decreased.

\subsection{Surface morphology of GWPU}

The results of surface morphology tests of GWPU films with different GMS content are presented in Fig. 9. When the content of GMS increased, the roughness of the film surface

Table 5 Surface energy of GWPU films with different GMS content

\begin{tabular}{lllll}
\hline Sample & $\begin{array}{l}\text { Contact angle } \\
\text { of water }\left(^{\circ}\right)\end{array}$ & $\begin{array}{l}\text { Contact angle } \\
\text { of formamide }\left(^{\circ}\right)\end{array}$ & $\begin{array}{l}\text { Contact angle of } \\
\text { diiodomethane }\left(^{\circ}\right)\end{array}$ \\
\hline GWPU-0 & 94.8 & 79.5 & 70.0 & $\begin{array}{l}\text { Surface energy } \\
\left(\mathrm{mN} \mathrm{m}^{-1}\right)\end{array}$ \\
GWPU-5 & 98.5 & 82.7 & 72.0 & 24.04 \\
GWPU-10 & 99.3 & 83.2 & 71.8 & 22.36 \\
GWPU-15 & 102.2 & 84.1 & 73.9 & 21.30 \\
GWPU-20 & 103.8 & 85.7 & 74.7 & 20.15 \\
GWPU-25 & 104.5 & 85.0 & 73.6 & 21.39 \\
GWPU-30 & 102.8 & 84.2 & &
\end{tabular}



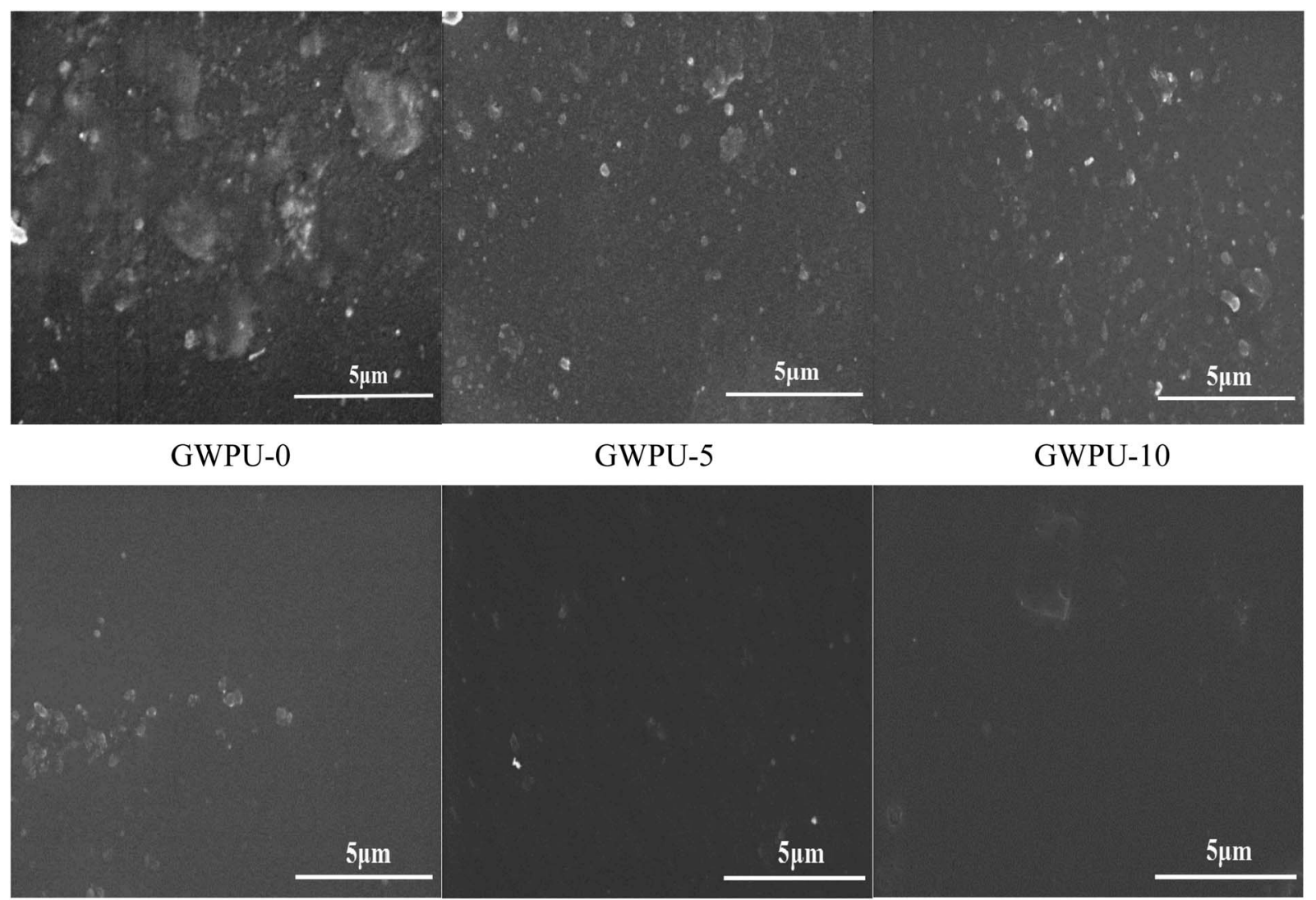

GWPU-15

GWPU-20

GWPU-25

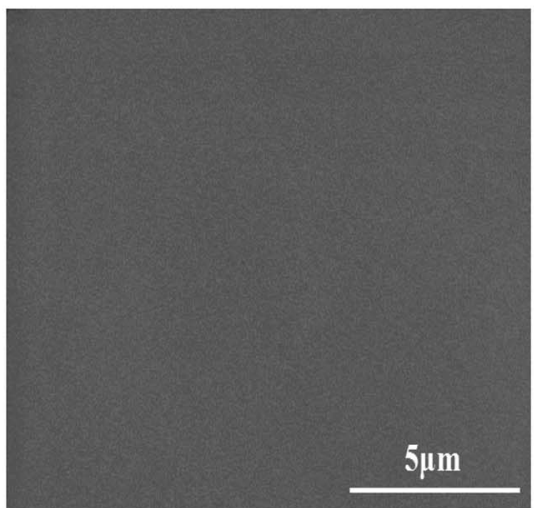

GWPU-30

Fig. 9 SEM images of GWPU films with different GMS content.

decreased, and the surface became more uniform. This occurred because with the increase in the GMS content, the long-chain alkane groups on the GMS were neatly arranged on the surface to form a uniform smooth surface. When the content of GMS was lower, the content of PDMS was relatively higher, and PDMS had a tendency to enrich on the surface during curing. Therefore, the surface of the films would appear uneven.

Table 6 Water repellency scores of padded fabrics with different GWPU samples

\begin{tabular}{|c|c|c|c|c|c|c|c|}
\hline Sample & GWPU-0 & GWPU-5 & GWPU-10 & GWPU-15 & GWPU-20 & GWPU-25 & GWPU-30 \\
\hline Score & 70 & 80 & 90 & 95 & 100 & 95 & 90 \\
\hline
\end{tabular}


Table 7 Air permeability of padded fabric coated with different GWPU emulsions

\begin{tabular}{llllllll}
\hline Sample & GWPU-0 & GWPU-5 & GWPU-10 & GWPU-15 & GWPU-20 & GWPU-25 & GWPU-30 \\
\hline$R\left(\mathrm{~mm} \mathrm{~s}^{-1}\right)$ & 125.4 & 117.8 & 129.2 & 131.1 & 128.3 & 119.3 & 132.4
\end{tabular}

\subsection{Water repellency of fabrics coated by GWPU}

The water repellency of fabric treated with GWPU was measured using a spray tester. It can be seen from the results in Table 6 that when the content of GMS increased, the water repellency score showed a slightly increasing trend because the greater long-chain alkane content and the larger amount of $-\mathrm{CH}_{2} \mathrm{CH}_{3}$

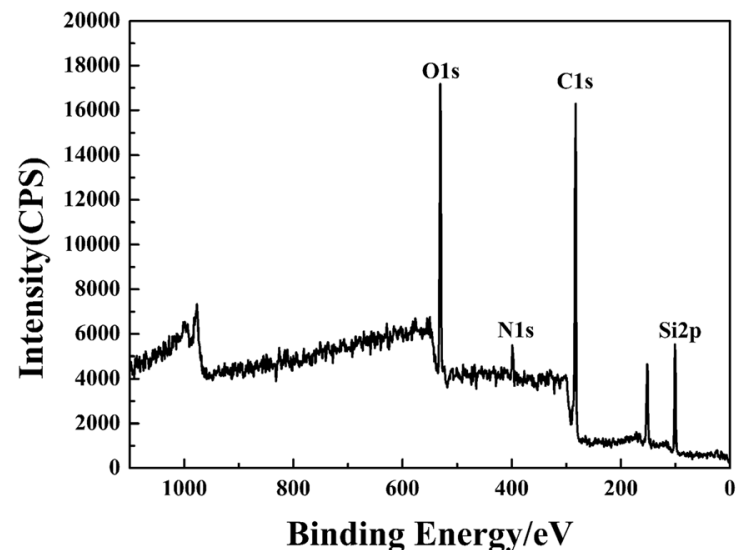

(a)

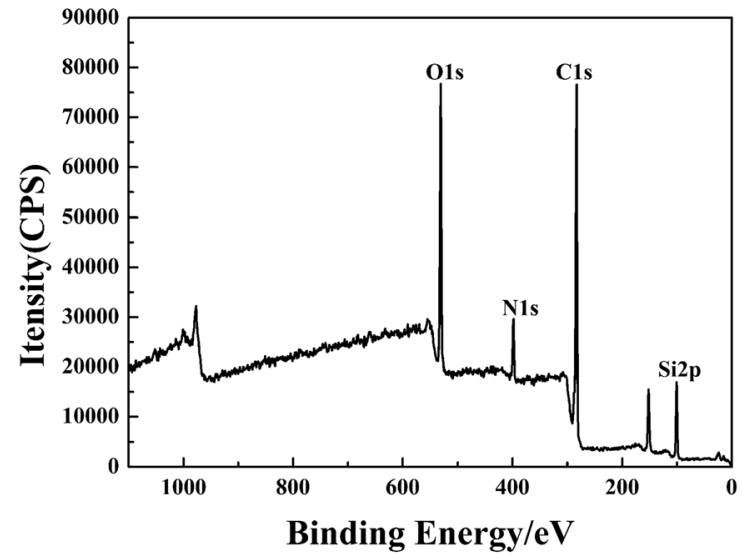

(c)

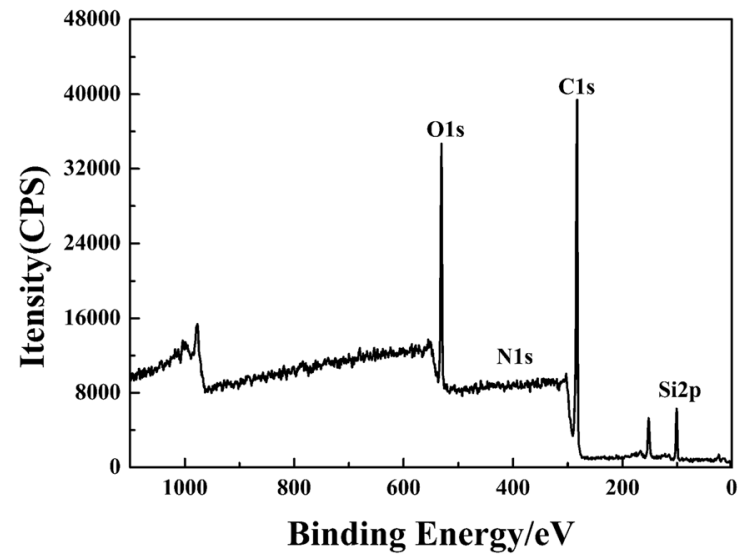

(e)

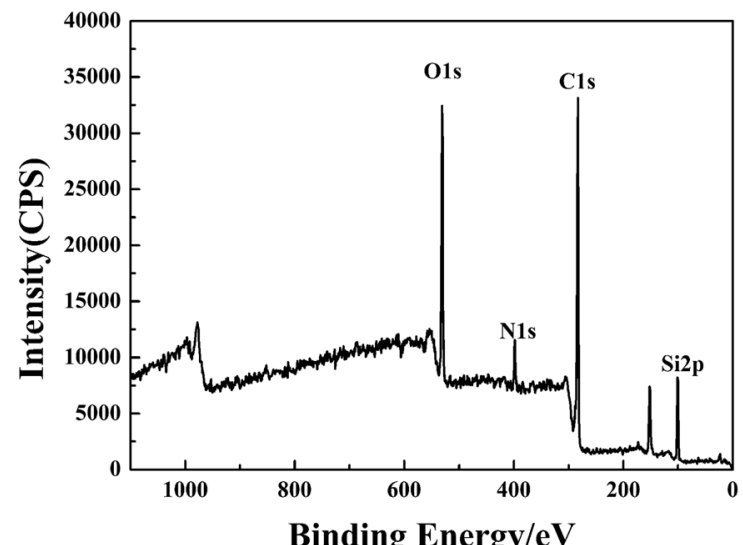

(b)

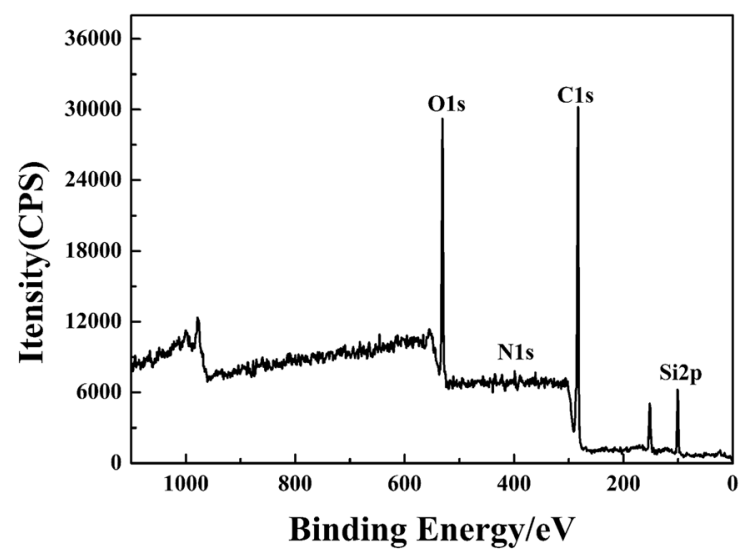

(d)

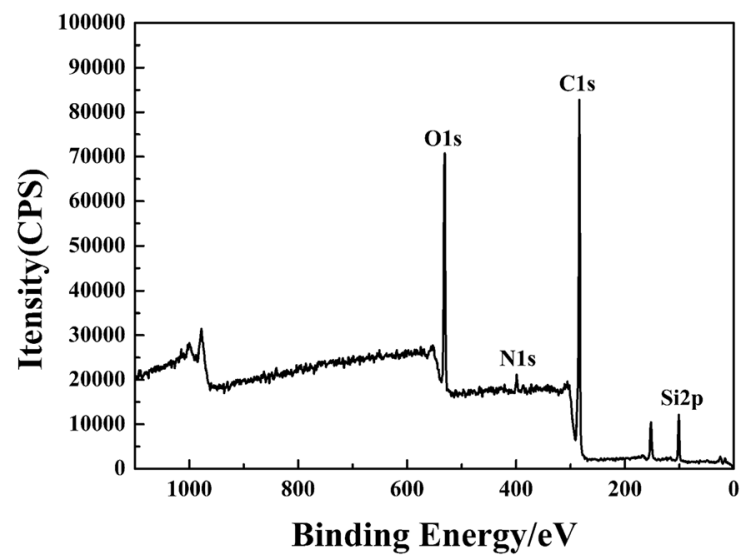

(f)

Fig. 10 The XPS full spectra of the GWPU-20 film and fabric: (a) film, take-off angle $=20^{\circ}$; (b) film, take-off angle $=40^{\circ}$; (c) film, take-off angle $=$ $90^{\circ}$; (d) fabric, take-off angle $=20^{\circ}$; (e) fabric, take-off angle $=40^{\circ}$; (f) fabric, take-off angle $=90^{\circ}$. 
Table 8 Atomic mass concentrations of the GWPU-20 film and fabric

\begin{tabular}{|c|c|c|c|c|c|c|}
\hline & Take-off angle $/^{\circ}$ & Depth/nm & \multicolumn{4}{|c|}{ Atomic mass concentration (\%) } \\
\hline & 40 & $\sim 6.4$ & 62.38 & 5.12 & 21.40 & 11.11 \\
\hline & 90 & $\sim 10.0$ & 63.85 & 6.44 & 20.55 & 9.16 \\
\hline GWPU-20-treated fabric & 20 & $\sim 3.4$ & 66.98 & 1.33 & 22.48 & 9.21 \\
\hline
\end{tabular}

orientationally aligned on the fabric surface to form an effective water-repellent layer. When the GMS content of GWPU was $20 \mathrm{wt} \%$, the water repellency score reached the maximum of 100. However, a further increase in the GMS content resulted in a relative decrease in the soft segment content in the system, and a weakness in the molecular heating motion flipping ability. In addition, the increase in the GMS content decreased the number of particles adhering to the fabric surface due to the larger size of the emulsion particles, and thus decreasing the water repellency of the GWPU films.

\subsection{Air permeability of fabric coated by GWPU}

The fabrics were coated by different GWPU emulsions, and the results of the air permeability tests are shown in Table 7. Compared with the uncoated fabric $\left(134 \mathrm{~mm} \mathrm{~s}^{-1}\right)$, the air permeability of padded fabrics was slightly reduced, which indicated that after padding, the fabric fibers were coated with the GWPU emulsion, while the gaps between the fibers were retained. Therefore, the fabric had a certain amount of gas permeability, and the air permeability was maintained above $110 \mathrm{~mm} \mathrm{~s}^{-1}$, which met the requirements of being waterproof and ventilated.

\subsection{Study on the mechanism of water repellency of GWPU}

According to the analysis of the above factors, the stronger water repellent was GWPU-20. In order to explore the mechanism of water repellency, the surface properties of GWPU film and the fabrics padded by GWPU emulsion were characterized by XPS. Then, a water repellency mechanism model was constructed based on the analysis of the effect of the surface elements and chemical structure on water repellency.

3.11.1 XPS of GWPU films and the fabrics coated by GWPU emulsion. The XPS full spectra of GWPU films and the fabrics coated by GWPU emulsions are shown in Fig. 10, and the atomic mass concentrations are listed in Table 8. From the peak position and elemental feature binding energy of Fig. 10, it can be seen that the Si content gradually increased with a decrease in the take-off angle, which indicated that the incorporated silicone segments tended to enrich on the top layer surfaces of GWPU film and fabrics treated with GWPU emulsion. In contrast, the elemental $\mathrm{N}$ content tended to decrease as the take-off angle decreased. This occurred because the elemental $\mathrm{N}$ was derived from - $\mathrm{NH}-\mathrm{COO}-$ and was a part of the hard segment of the polyurethane, which was mainly distributed in the inner layer.
In order to further obtain the surface element distribution information for the film and the finishing fabric, peak fitting of the $\mathrm{C}$ elements was performed and is shown in Fig. 11. According to the reports, the binding energy of the $\mathrm{C}$ elements in polyurethane was mainly divided into three types: the absorption peaks of $\mathrm{C}-\mathrm{C} / \mathrm{C}-\mathrm{H},-\mathrm{C}-\mathrm{O}-$ and $-\mathrm{COO}-/-$ NCOO- appeared at 284.4-284.8 eV, 285.6-286.4 eV and 287.5-289.2 eV, respectively. The peak fitting results of $\mathrm{C} 1 \mathrm{~s}$ of the GWPU-20 film and the finishing fabric are summarized in Table 9 and Table 10, respectively. It can be seen that as the take-off angle decreased, the -COO-/-NCOO- and -C-Owere lower, while the $\mathrm{C}-\mathrm{C} / \mathrm{C}-\mathrm{H}$ was higher, which indicated that the urethane bond and the ester group of the hard segment were concentrated on the relatively inner side while the structures such as $-\mathrm{CH}_{3}$ and $-\mathrm{CH}_{2} \mathrm{CH}_{3}$ were concentrated on the surface. The results further confirmed the mechanism by which $-\mathrm{CH}_{3}$ and $-\mathrm{CH}_{2} \mathrm{CH}_{3}$ were aligned to the surface to produce the water repellent.

3.11.2 Construction of the GWPU water repellent model. According to the surface element analysis results of the GWPU film and the application evaluation results of the GWPU water repellent, a schematic diagram of the water repellency mechanism was constructed, and is shown in Fig. 12. It can be seen that an effective water-repellent layer was formed on the surface of the fabric finished with GWPU. The urethane structure at the bottom of the layer provided such a strong adhesion ability that the waterrepellent molecules were immobilized on the surface of the fabric. The water-repellent layer mainly comprised a two-part structure, one of which was a long-chain alkane structure from glyceryl monostearate (GMS), and the other was the hydrophobic silicone segment. On the one hand, the long-chain alkane structure was oriented toward the surface during the high-temperature baking process to form a regular structure. The $-\mathrm{CH}_{2} \mathrm{CH}_{3}$ group, which was the end group of the long-chain alkane, was directed to the air, effectively preventing the water droplets from invading the surface of the fabric fiber. On the other hand, the silicone segment, which possessed good flexibility and low surface energy, enriched on the surface and reduced the surface energy of the fabric during the baking process.

Furthermore, there were two $-\mathrm{CH}_{3}$ groups on each silicon atom, and hydrophobic $-\mathrm{CH}_{3}$ was regularly arranged on the silicone molecular chain. The $\mathrm{Si}-\mathrm{C}$ bond on the silicon atom could freely rotate, and the three hydrogen atoms on each $-\mathrm{CH}_{3}$ expanded 


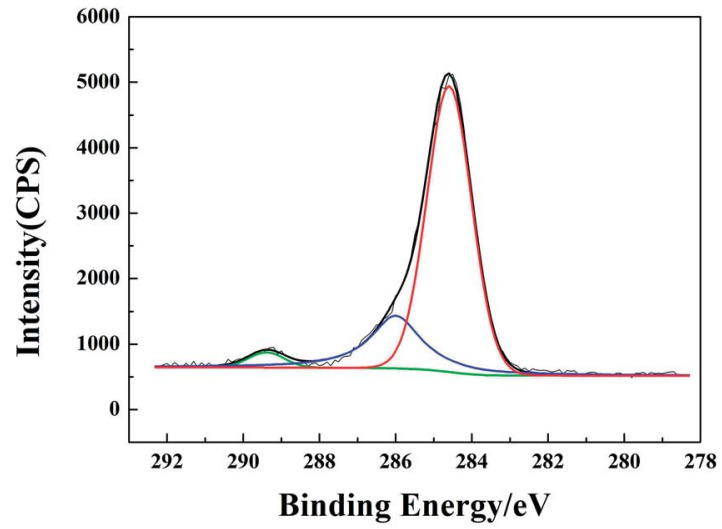

(a)

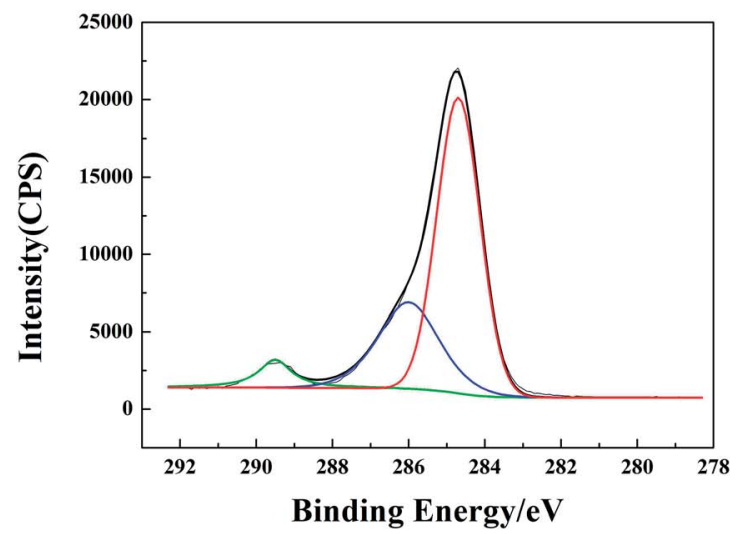

(c)

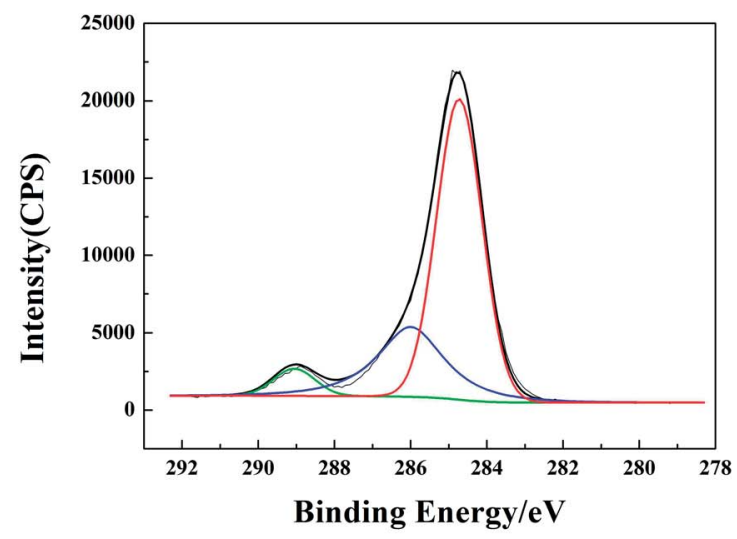

(e)

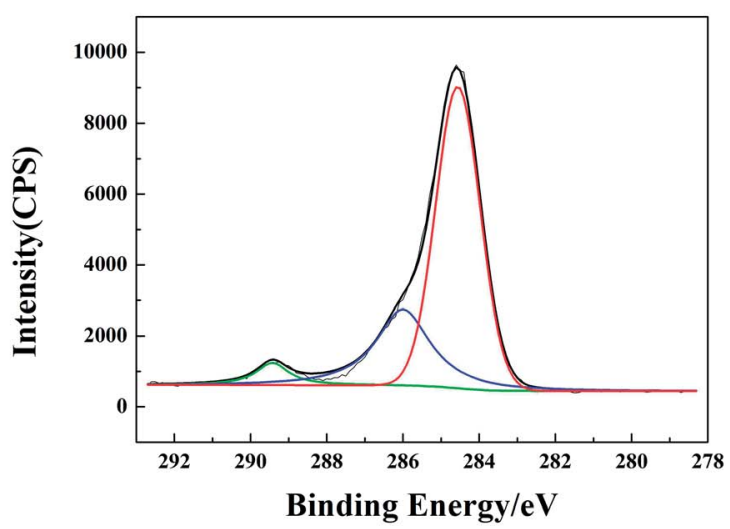

(b)

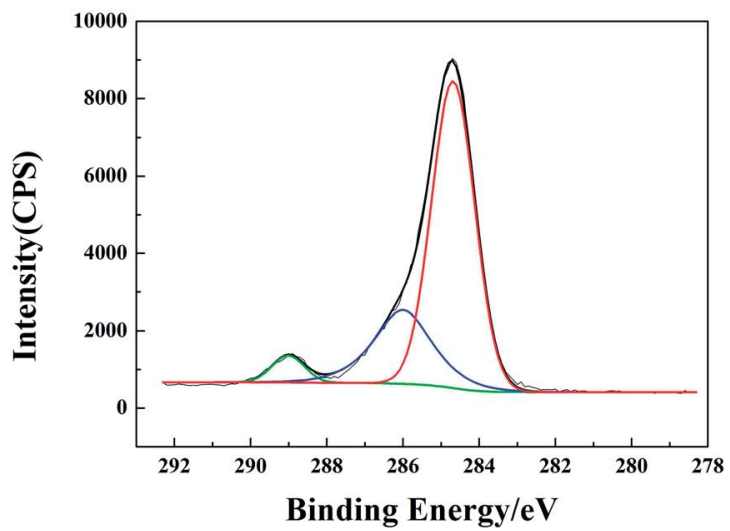

(d)

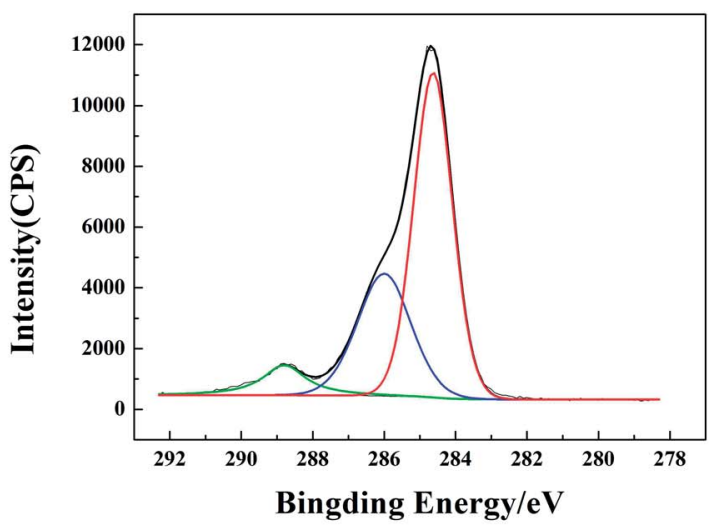

(f)

Fig. $11 \mathrm{C}$ 1s peak fitting of the GWPU film and the fabric with different take-off angles: (a) film, take-off angle $=20^{\circ}$; (b) film, take-off angle $=40^{\circ}$; (c) film, take-off angle $=90^{\circ}$; (d) fabric, take-off angle $=20^{\circ}$; (e) fabric, take-off angle $=40^{\circ}$; (f) fabric, take-off angle $=90^{\circ}$.

outward like an umbrella, effectively preventing the intrusion of water molecules. It was observed that the combination of the silicone segment and the long-chain alkane exerted a synergistic waterrepellent effect.

\section{Conclusions}

Glyceryl monostearate-modified waterborne polyurethane as a water repellent was successfully prepared by selfemulsification. With an increase in the GMS content, the particle size of the emulsion tended to decrease and then increase, while the behavior of the viscosity was the opposite. The water resistance of the GWPU films was increased by the addition of GMS with a great amount of hydrophobic long-chain alkanes. An increase in the GMS content resulted in an increase in the water contact angles of fabrics coated with GWPU. Among these, the water contact angle of terylene coated by GWPU-20 was the largest, at $148.0^{\circ}$. The water repellent grade of the padded fabric increased and then decreased with an increase in the GMS content in the water repellent; fabric treated with 
Table 9 C 1s peak fitting results of GWPU-20 film with different takeoff angles

\begin{tabular}{lllll}
\hline & & \multicolumn{3}{l}{$\begin{array}{l}\text { Mass concentration of C 1s peak } \\
\text { fitting/\% }\end{array}$} \\
\cline { 3 - 5 } & & -COO-/-NCOO- & -C-O- & C-C/C-H \\
\hline Take-off angle ${ }^{\circ}$ & Depth/nm & -CO & 22.53 & 74.35 \\
20 & $\sim 3.4$ & 3.12 & 26.99 & 67.69 \\
40 & $\sim 6.4$ & 5.32 & 28.32 & 64.94 \\
90 & $\sim 10.0$ & 6.74 & &
\end{tabular}

Table 10 C 1s peak fitting results of the fabric treated by GWPU-20 with different take-off angles

\begin{tabular}{|c|c|c|c|c|}
\hline \multirow[b]{2}{*}{ Take-off angle ${ }^{\circ}$} & \multirow[b]{2}{*}{ Depth/nm } & \multicolumn{3}{|c|}{$\begin{array}{l}\text { Mass concentration of } \mathrm{C} 1 \text { s peak } \\
\text { fitting/\% }\end{array}$} \\
\hline & & -COO-/-NCOO- & $-\mathrm{C}-\mathrm{O}-$ & $\mathrm{C}-\mathrm{C} / \mathrm{C}-\mathrm{H}$ \\
\hline 20 & $\sim 3.4$ & 4.62 & 24.85 & 70.53 \\
\hline 40 & $\sim 6.4$ & 5.53 & 26.89 & 67.58 \\
\hline 90 & $\sim 10.0$ & 7.87 & 31.53 & 60.59 \\
\hline
\end{tabular}

GWPU-20 achieved the highest grade (100) and also exhibited good air permeability. The mechanism of water repellency indicated that a synergistic water-repellent effect was obtained from the combination of the silicone segment and the longchain alkane.

\section{Conflicts of interest}

There are no conflicts to declare.

\section{References}

1 M. Irfan, S. Perero, M. Miola, G. Maina, A. Ferri, M. Ferraris and C. Balagna, Antimicrobial functionalization of cotton fabric with silver nanoclusters/silica composite coating via RF co-sputtering technique, Cellulose, 2017, 24, 2331-2345.

2 D. Lv, R. X. Wang, G. S. Tang, Z. P. Mou, J. D. Lei, J. Q. Han, S. De Smedt, R. H. Xiong and C. B. Huang, Ecofriendly Electrospun Membranes Loaded with Visible-Light Responding Nanoparticles for Multifunctional Usages: Highly Efficient Air Filtration, Dye Scavenging, and Bactericidal Activity, ACS Appl. Mater. Interfaces, 2019, 11, 12880-12889.

3 M. Zhu, J. Han, F. Wang, W. Shao, R. Xiong, Q. Zhang, H. Pan, Y. Yang and S. K. Samal, Electrospun nanofibers membranes for effective air filtration, Macromol. Mater. Eng., 2017, 302, 1600353-1600380.

4 D. Lv, M. M. Zhu, Z. C. Jiang, S. H. Jiang, Q. L. Zhang, R. H. Xiong and C. B. Huang, Green Electrospun Nanofibers and Their Application in Air Filtration, Macromol. Mater. Eng., 2018, 303, 1800336-1800354.

5 G. N. Kousalya, M. R. Gandhi, C. S. Sundaram and S. Meenakshi, Synthesis of nano-hydroxyapatite chitin/ chitosan hybrid biocomposites for the removal of $\mathrm{Fe}(\mathrm{III})$, Carbohydr. Polym., 2015, 117, 160-168.

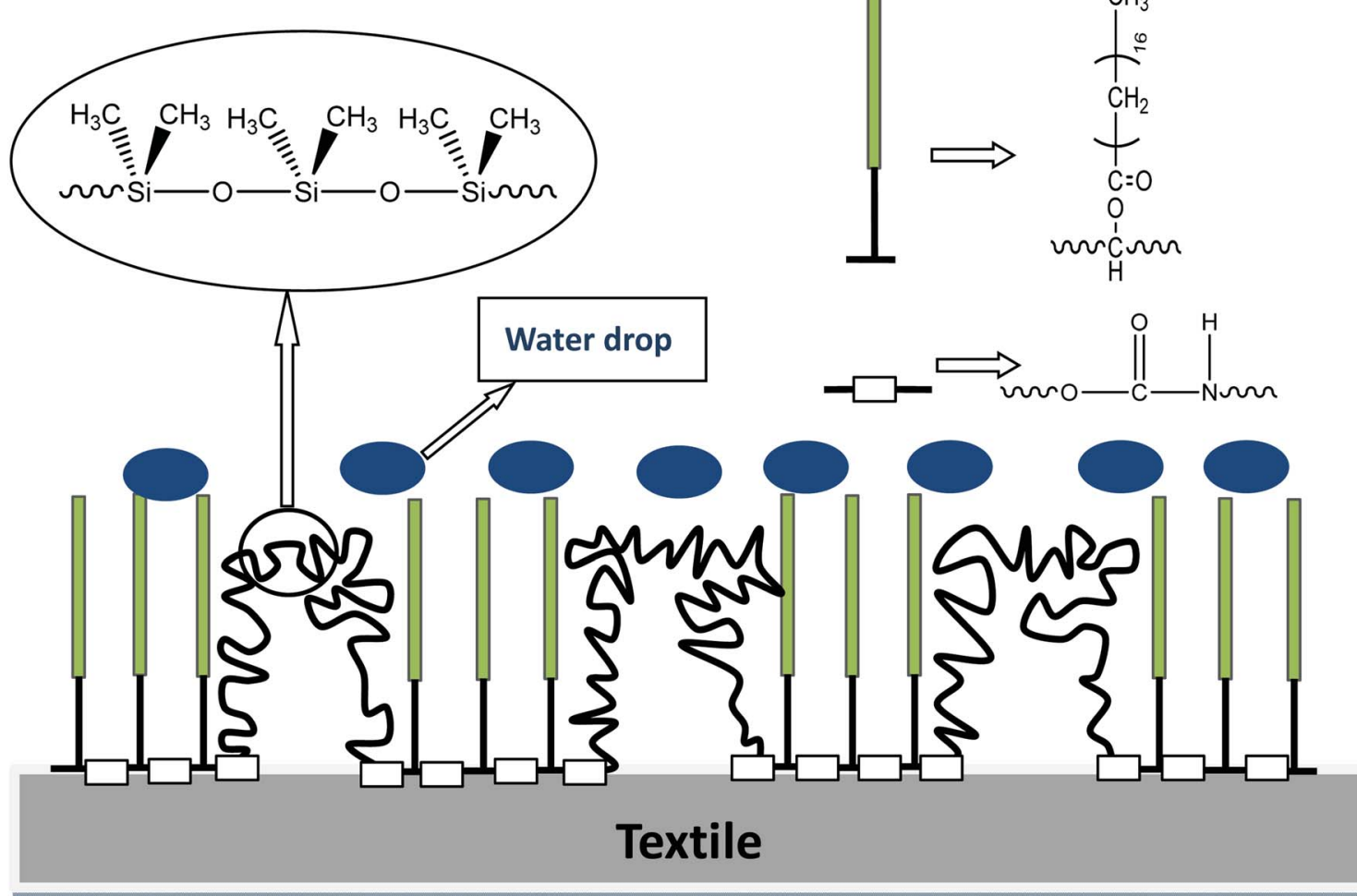

Fig. 12 A schematic diagram of the mechanism of the GWPU water repellent. 
6 M. Gorensek and P. Recelj, Nanosilver Functionalized Cotton Fabric, Text. Res. J., 2007, 77, 138-141.

7 F. Ferrero, M. Periolatto, M. Sangermano and M. B. Songia, Water-repellent finishing of cotton fabrics by ultraviolet curing, J. Appl. Polym. Sci., 2008, 107, 810-818.

8 M. Zhang, J. Li, D. Zang, Y. Lu, Z. Gao and J. Shi, Preparation and characterization of cotton fabric with potential use in UV resistance and oil reclaim, Carbohydr. Polym., 2016, 137, 264-270.

9 L. R. Scarratt, B. S. Hoatson, E. S. Wood, B. S. Hawkett and C. Neto, Durable Superhydrophobic Surfaces via Spontaneous Wrinkling of Teflon, ACS Appl. Mater. Interfaces, 2016, 8, 6743-6750.

10 B. Simončič, B. Tomšič, L. Černe, B. Orel, I. Jerman, J. Kovač, M. Žerjav and A. Simončič, Multifunctional water and oil repellent and antimicrobial properties of finished cotton: influence of sol-gel finishing procedure, J. Sol-Gel Sci. Technol., 2012, 61, 340-354.

11 L. Wang, Y. Shen, X. Lai, Z. Li and M. Liu, Synthesis and properties of crosslinked waterborne polyurethane, $J$. Polym. Res., 2011, 18, 469-476.

12 W. Tang, Y. Huang and F. Qing, Synthesis and characterization of fluorinated polyacrylate graft copolymers capable as water and oil repellent finishing agents, J. Appl. Polym. Sci., 2011, 119, 84-92.

13 W. Jiang, Y. Huang, G. Gu, W. Meng and F. Qing, A novel waterborne polyurethane containing short fluoroalkyl chains: Synthesis, characterization and its application on cotton fabrics surface, Appl. Surf. Sci., 2006, 253, 2304-2309.

14 Y. Xu, H. Yin, S. Yuan and Z. Chen, Film morphology and orientation of amino silicone adsorbed onto cellulose substrate, Appl. Surf. Sci., 2009, 20, 8435-8442.

15 P. Mazeyar and H. Roozbeh, Macro-and Microemulsion Silicone Softeners on Polyester Fibers: Evaluation of Different Physical Properties, J. Surfactants Deterg., 2008, 4, 269-273.

16 C. Sawatari, Y. Sekiguchi and T. Yagi, Durable WaterRepellent Cotton Fabrics Prepared by Low-Degree Substitution of Long Chain Alkyl Groups, Text. Res. J., 1998, 68, 508-514.

17 T. Nakagawa and T. Hiwatashi, Water-repellent thin films from mixtures of fluoroalkylmethoxysilane and bis(trialkoxysilyl)alkanes of various carbon-chain lengths using the sol-gel method and the fluoroalkylmethoxysilane dispersion mechanism, J. Non-Cryst. Solids, 2003, 316, 0-237.

18 D. K. Kim, S. B. Lee and K. S. Doh, Surface Properties of Fluorosilicone Copolymers and Their Surface Modification Effects on PVC Film, J. Colloid Interface Sci., 1998, 205, 417-422.

19 S. Xiong, X. Guo, L. Li, S. Wu, P. Chu and Z. Xu, Preparation and characterization of fluorinated acrylate copolymer latexes by miniemulsion polymerization under microwave irradiation, J. Fluorine Chem., 2009, 3, 417-425.

20 S. Peng, L. Song, Y. Wang, L. Ji, M. Xu and R. Zhang, The suspension-emulsion combined polymerization of fluorinated acrylic monomer and the fluorinated latex film surface properties, Colloid Polym. Sci., 2011, 2, 149-157.

$21 \mathrm{M}$. Zhu, F. Qing and W. Meng, Novel Waterborne Polyurethanes Containing Short Fluoroalkyl Chains: Synthesis and Applications on Cotton Fabrics, J. Appl. Polym. Sci., 2008, 109, 1911-1915.

22 H. Wang, W. Liu, J. Tan and G. Xiahou, Synthesis and Characterization of Novel UV-curable Fluorinated Polyurethane-acrylate Copolymer, Chem. Res. Chin. Univ., 2016, 32, 311-317.

23 N. Li, F. Zeng, Y. Wang, D. Qu, W. Hu, Y. Luan, S. Dong, J. Zhang and Y. Bai, Fluorinated polyurethane based on liquid fluorine elastomer (LFH) synthesis via two-step method: the critical value of thermal resistance and mechanical properties, RSC Adv., 2017, 49, 30970-30978.

24 S. Tragoonwichian, P. Kothary, A. Siriviriyanun, E. A. O'Rear and N. Yanumet, Silicon-compound coating for preparation of water repellent cotton fabric by admicellar polymerization, Colloids Surf., A, 2011, 384, 381-387.

25 Z. Li, Y. Xing and J. Dai, Superhydrophobic surfaces prepared from water glass and non-fluorinated alkylsilane on cotton substrates, Appl. Surf. Sci., 2008, 254, 2131-2135.

26 A. Noreen, K. M. Zia, M. Zuber, S. Tabasum and M. J. Saif, Recent trends in environmentally friendly water-borne polyurethane coatings: A review, Korean J. Chem. Eng., 2016, 33, 388-400.

27 J. C. Lötters, W. Olthuis, P. H. Veltink and P. Bergveld, The mechanical properties of the rubber elastic polymer polydimethylsiloxane for sensor applications, J. Micromech. Microeng., 1997, 7, 145-147.

28 L. J. Thomsen, T. Schaefer and H. G. Kristensen, Prolonged Release Matrix Pellets Prepared by Melt Pelletization II. Hydrophobic Substances as Meltable Binders, Drug Dev. Ind. Pharm., 1994, 20, 19.

29 W. Lei, Y. Sun, B. Huang and X. Zhou, Synthesis and application of polyurethane-modified silicone as finishing agent for cotton fabric, Fibers Polym., 2018, 19, 1024-1031.

30 H. M. Fahmy, A. A. Aly, A. Amr, S. M. Sayed and A. M. Rabie, SA/TDI/PEG adducts as water repellent finishes for cotton/ polyester blended fabric, Prog. Org. Coat., 2016, 99, 166-172.

31 M. Rabnawaz, G. Liu and H. Hu, Fluorine-Free Anti-Smudge Polyurethane Coatings, Angew. Chem., Int. Ed., 2015, 54, 12722-12727.

$32 \mathrm{H}$. Liu, Z. Wang and C. Sun, Robust water-repellent treatment of cotton fabrics with polysiloxane modified via thiol-ene click reaction, Fibers Polym., 2018, 19, 580-586.

33 F. Z. Sidouni, N. Nurdin, P. Chabrecek, D. Lohmann, J. Vogt, N. Xanthopoulos, H. J. Mathieu, P. Francois, P. Vaudaux and P. Descouts, Surface properties of a specially modified highgrade medical polyurethane, Surf. Sci., 2001, 491, 355-369.

34 K. Wang, Y. Dong, Y. Yan, W. Zhang, C. Qi, C. Han, J. Li and S. Zhang, Highly hydrophobic and self-cleaning bulk wood prepared by grafting long-chain alkyl onto wood cell walls, Wood Sci. Technol., 2017, 51, 395-411. 